\title{
Inventing a new type of platform gate
}

\author{
K. Kimura \& M. Inoue \\ Railway System Planning Department, \\ West Japan Railway Company, Japan
}

\begin{abstract}
Automatic platform gates are recognized as one of the most efficient hardware to reduce accidents on platforms, as they prevent customers from falling from the platform or coming into contact with arriving or departing trains. West Japan Railway Company (JR-West), who has been trying to increase their safety level and whose fiscal 2018 (ending March 2018) safety target includes 30 per cent reduction of platform accidents from 13 in fiscal 2013, has been installing platform gates into several stations.

However, these "door style" platform gates, which cannot accommodate rail cars with different door configurations, are not appropriate for stations on the company's major lines because the number of doors or train cars is different depending on the services such as local or rapid. Having taken this issue into account, JR-West invented a new type of platform gate; the "wire style". These platform gates enable passengers to keep away from moving trains, being operated by wires which are raised when the trains stop at the platform.

The first on-site test was completed in Sakurajima station on a minor line in the Osaka-Kyoto metropolitan area, which 18,000 passengers use every day and where only 8-car-trains stop. Reviewing its result, JR-West started a second onsite test in Rokkomichi station on one of the most major lines between Osaka and Kobe, which 50,000 passengers use and where 230 trains with 6, 7, 8, 10 and 12 cars stop every day. As the result, it is assessed to be sufficient from the viewpoint of their performance and the influence on passenger flow and train operation, JR-West is considering further installation into other stations so that accidents on platforms will decrease.

Keywords: platform gates, wire, TASK, different number of door, different car configurations, sensor, Sakurajima, Rokkomichi, JR-West, Nippon Signal.
\end{abstract}




\section{Introduction}

Automatic platform gates are recognised as one of the most effective ways of reducing accidents on platforms, as they prevent customers from falling from the platform or coming into contact with arriving or departing trains.

As is recorded by the Ministry of Land, Infrastructure, Transport and Tourism in Japan [3], the first platform gates in Japan were installed in 1974 at Atami Station for the Shinkansen bullet train. However, platform gates for the commuter railways had not been set up until 1991, where they were first installed at the newly constructed Tokyo Metro Line. In 2000, Tokyu Corporation and Toei Subway set up platform gates in their existing stations, and other railway operators in Tokyo started adding platform gates to their lines as well.

Following the installation of platform gates by several railway operators, the Committee to Promote Platform Doors established guidelines for the installation of platform gates in its interim report (the Ministry of Land, Infrastructure, Transport and Tourism in Japan [2]). It recommended that railway operators add platform gates to stations that served over 100,000 passengers per day, if the trains were equipped with ATO (Automatic Train Operation) or TASC (Train Automatic Stop-position Controller) and their door locations were standardised.

\subsection{Urban transport of JR-West}

JR-West was established in 1987, succeeding the western one fourth of the former Japanese National Railways (JR-West [4]). As a result, their operation covers not only dense urban areas, but suburban and rural areas as well.

In Japan, the rail share of all modes of passenger transport remains at 28 per cent as is shown in the statistics of Institute for Transport Policy Studies [1]. It is because those living in suburban areas that surround large cities typically commute to the city centre by rail. As a result, JR-West offers transportation services to 270,000 passengers per day in the Osaka-Kyoto metropolitan area.

\subsection{Lines and number of passengers}

Figure 1 shows the number of passengers at major stations (over 30,000 per day) in the company's Osaka-Kyoto metropolitan network.

The main trunk line is the Himeji (shown as "H") - Osaka - Maibara ("M") line, whose route length is $198 \mathrm{~km}$. JR-West's special rapid service runs between the major stations at a maximum speed of $130 \mathrm{~km} / \mathrm{h}$. The local service, which stops at every station along the "N" - Osaka - "T" route, runs at a maximum speed of $110 \mathrm{~km} / \mathrm{h}$. 


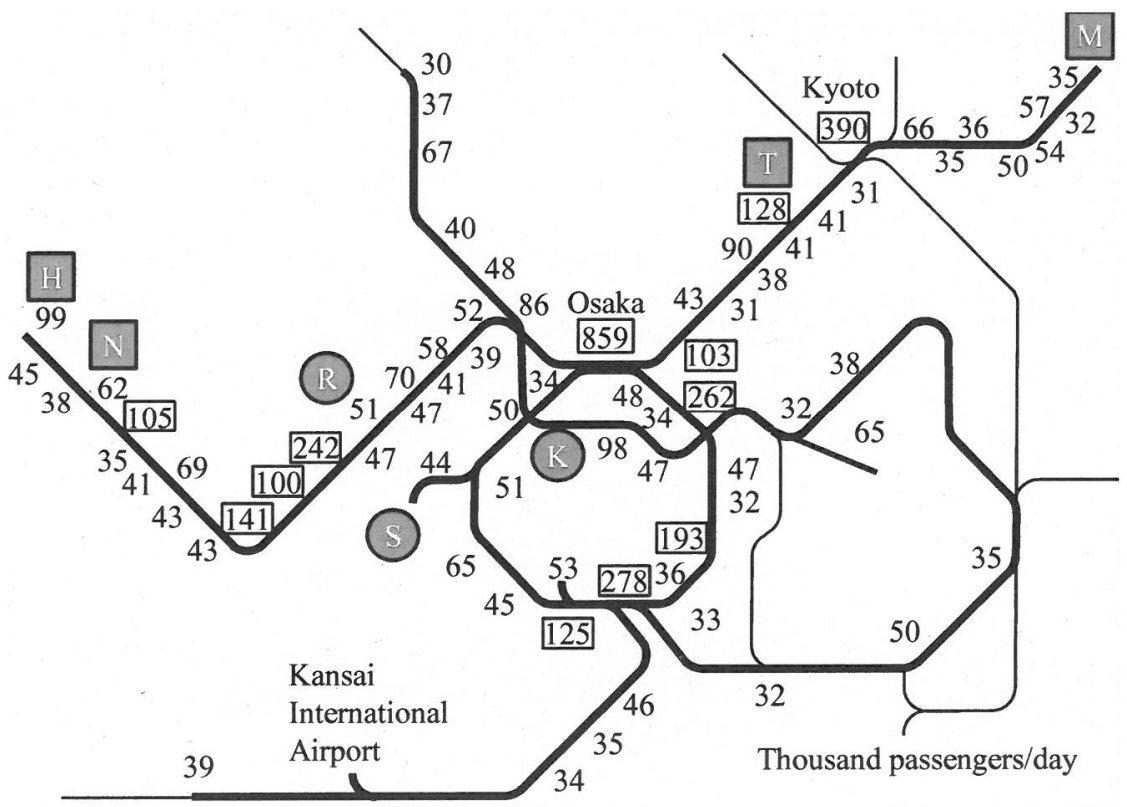

Figure 1: Number of passengers in the Osaka-Kyoto metropolitan area.

Table 1: Commuter trains of JR-West's Osaka-Kyoto metropolitan area.

\begin{tabular}{|l|c|c|c|c|c|c|}
\hline & Series & $\begin{array}{c}\text { Doors } \\
\text { per car }\end{array}$ & $\begin{array}{c}\text { Car } \\
\text { configurations }\end{array}$ & Debut & Renewal & $\begin{array}{c}\text { Number } \\
\text { of cars }\end{array}$ \\
\hline \multirow{2}{*}{$\begin{array}{l}\text { For Rapid } \\
\text { Services }\end{array}$} & 221 & 3 & $4 / 6 / 8,(10 / 12)$ & 1989 & 2012 & 474 \\
\cline { 2 - 7 } & 223 & 3 & $4 / 6 / 8,(10 / 12)$ & 1993 & & 400 \\
\cline { 2 - 7 } & 225 & 3 & $4 / 6 / 8,(10 / 12)$ & 2010 & & 226 \\
\hline For Local & 201 & 4 & 7 & 1974 & 2003 & 224 \\
\cline { 2 - 7 } Services & 205 & 4 & $4 / 6$ & 1986 & 2011 & 44 \\
\cline { 2 - 7 } & 207 & 4 & 7 & 1991 & & 477 \\
\cline { 2 - 7 } & 321 & 4 & 7 & 2005 & & 273 \\
\hline
\end{tabular}

\subsection{Types of trains}

The types and numbers of commuter trains that JR-West operates in the OsakaKyoto metropolitan area are shown in Table 1. Trains for rapid services are operated by 3 door cars, with 4, 6, 8, 10 or 12 car configurations, depending upon the number of passengers. Trains for local services are operated by 4 door cars, mostly in 7 car configurations.

Installing ATO or TASK to existing trains costs from $£ 65,000$ to $£ 170,000$ (from $€ 87,000$ to $€ 227,000$ ) per car, depending on their braking system. Due to the large number of cars operated by the company, it is not cost-effective to do so. 


\section{JR-West safety countermeasures}

The company had to develop some countermeasures to improve the level of safety on their platforms.

\subsection{Standardising train sets}

In March 2011, JR-West installed its first platform gates for commuters at KitaShinchi Station on the Tozai Line ("K" in Figure 1). As the station is located in Osaka's "Soho" area with lots of bars and restaurants, eight passengers fell from the platform in one year, the largest number of such occurrences in any of JRWest's stations. To install platform gates in the station, the company changed their rapid service trains from 3 door to 4 door cars in a 7 car configuration.

As the station is located underground and in a flat area, the company requested that their drivers stop the trains with an accuracy of $+/-750 \mathrm{~mm}$ from the designated stopping marker.

\subsection{Inventing a new type of platform gate}

However, changing all long distance trains to 4 door cars was not an acceptable solution to the company, and so they embarked on inventing a new type of platform gate, the "wire style", in cooperation with Nippon Signal Co., Ltd. These platform gates keep passengers away from moving trains by a wire barrier, which is raised when the train stops at the platform.

The first on-site test was conducted at Sakurajima Station, located on a minor line in the Osaka metropolitan area, which is used by 18,000 passengers every day and where only 8-car-trains stop ("S" in Figure 1). After reviewing the test results, JR-West started a second round of on-site testing in Rokkomichi Station (" $R$ " in Figure 1). This station is used by 50,000 passengers daily, with 230 train stops consisting of $6,7,8,10$ and 12 cars.

\section{Mechanical characteristics of the new platform gate}

This chapter describes the mechanical characteristics of the newly invented "wire style" platform gate and its design process.

\subsection{Gate size}

Installation of the platform gates is recommended in only 3.6 per cent (12) of the stations in the company's Osaka-Kyoto metropolitan area, and it is not economically feasible to install platform gates in every station because of their cost. So, the operating procedures of drivers and conductors at stations with platform gates are required to be the same as those at stations without the gates.

The gates are programmed to be opened automatically when a train arrives and stops at the station. The conductor checks that the train has stopped in the correct position and then opens the train's doors. Once he/she has confirmed that the passengers have finished getting off and on the train, the conductor closes the 
platform gates and the train doors, and sends a signal of "transfer of passengers finished" to the driver.

Considering these procedures, it is very important that the entire platform be visible from the conductor's position, and so the height of the new wire style platform gate was set as the same height of $1,300 \mathrm{~mm}$ as the conventional Japanese door style platform gate. The maximum height of the extended pillar was set at $2,300 \mathrm{~mm}$ and the height of the lowest wire with the pillar extended was set at $2,000 \mathrm{~mm}$, which is $150 \mathrm{~mm}$ higher than the height of train doors (Figure 2).

Each gate consists of four synchronised pillars that span 20 meters, the length of the company's commuter cars. To give drivers $+/-1,000 \mathrm{~mm}$ allowance from the stopping marker, the widest distance between pillars was set to 8.5 meters at Rokkomichi Station, where rapid and local service trains stop (Figure 3).

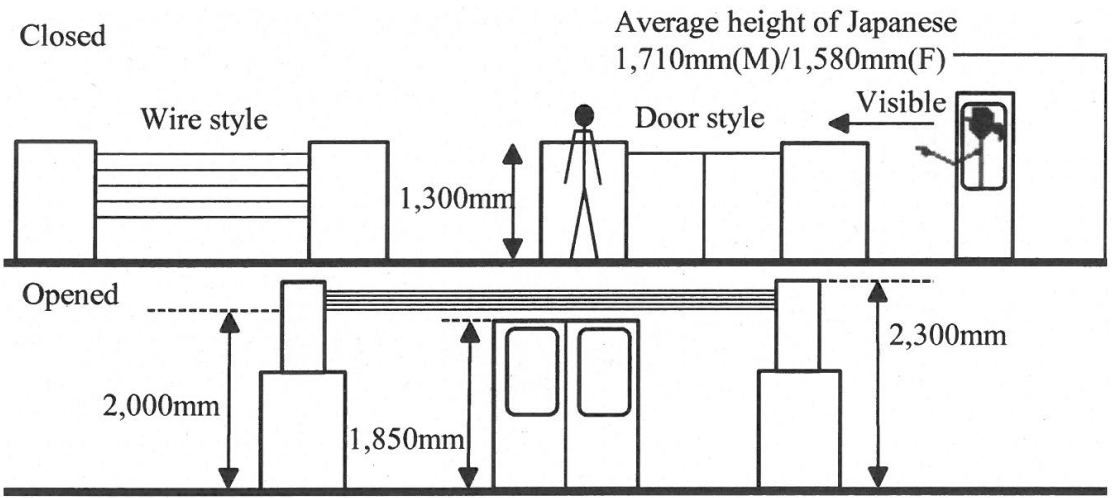

Figure 2: Height of the new platform gate.
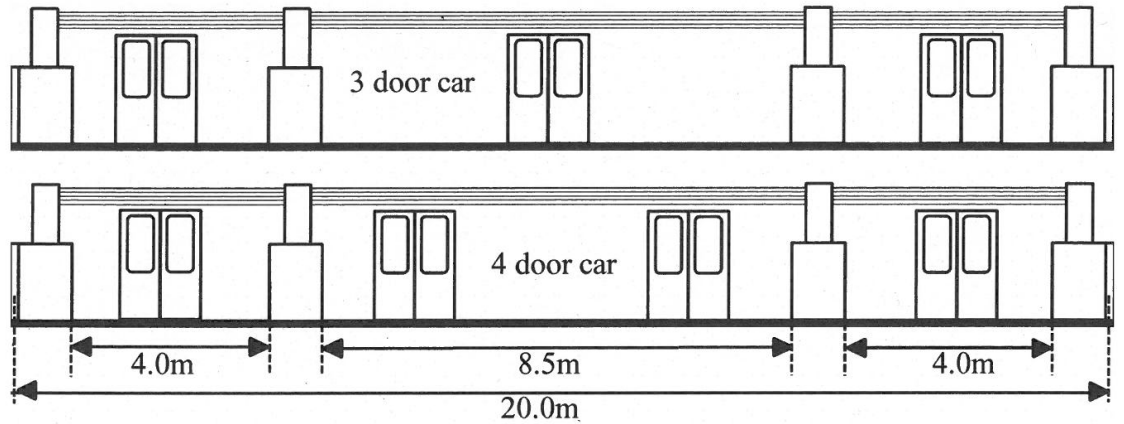

Figure 3: Alignment of platform gate pillars with doors. 
The pillars at the ends of each gate are joined to adjacent bodies to add rigidity. However, the two middle pillars are U-shaped to allow the wires to pass through, which slightly lessen their rigidity. To insure adequate strength when extended, the bottom sections required a certain depth, and so the lowest wire's height when the pillars are folded was fixed to $500 \mathrm{~mm}$.

Some station platforms do not have enough space to accommodate platform gates. In these cases, it was determined that a body $250 \mathrm{~mm}$ wide would provide both a proper fit and adequate strength.

Many of JR-West's station platforms had earth-filled foundations, which required additional reinforcement in order to support the platform gates. To reduce such costs, the bodies were lightened by adopting a coil spring instead of a balance weight device for the pillar.

\subsection{Movement of the wire mechanism}

When the wire style platform gate operates, the bottom wire must raise $1,500 \mathrm{~mm}$ even though the pillar itself only extends $1,000 \mathrm{~mm}$. To enable this action with a simple mechanism, movable pulleys are utilised. Stability and durability tests resulted in the adoption of 50mm diameter pulleys, and the number of wires was fixed to five, spaced at $175 \mathrm{~mm}$ when the gates are closed (Figure 4).

\subsection{Elongation of wires}

To decrease weight, kevlar-stainless steel wires with a tensile strength of over $30 \mathrm{kN}$ were chosen for the gates. When an external force is applied, the wires are counterbalanced by springs, which provide a force of $980 \mathrm{~N}$ to prevent passengers from contacting the trains (Figure 5).

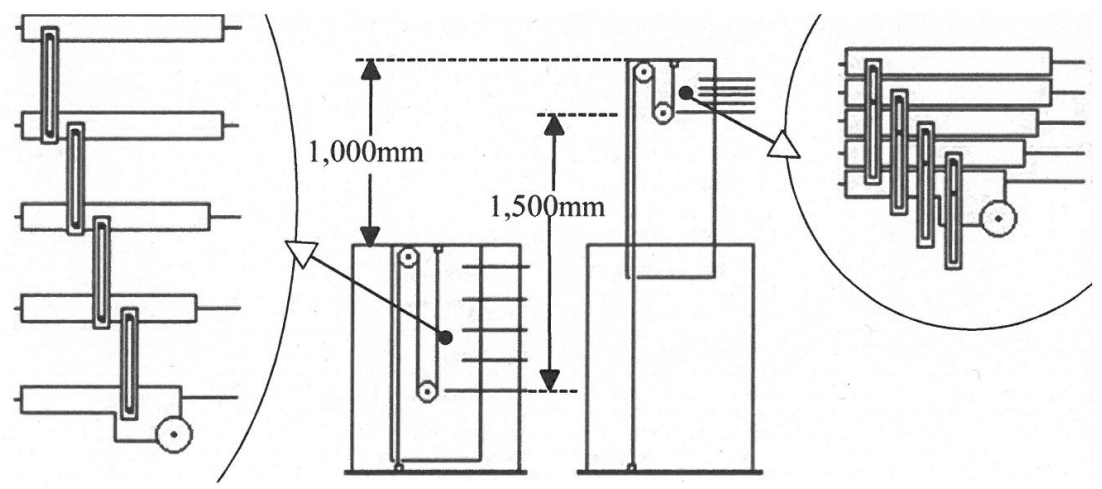

Figure 4: Movable pulleys for wires. 


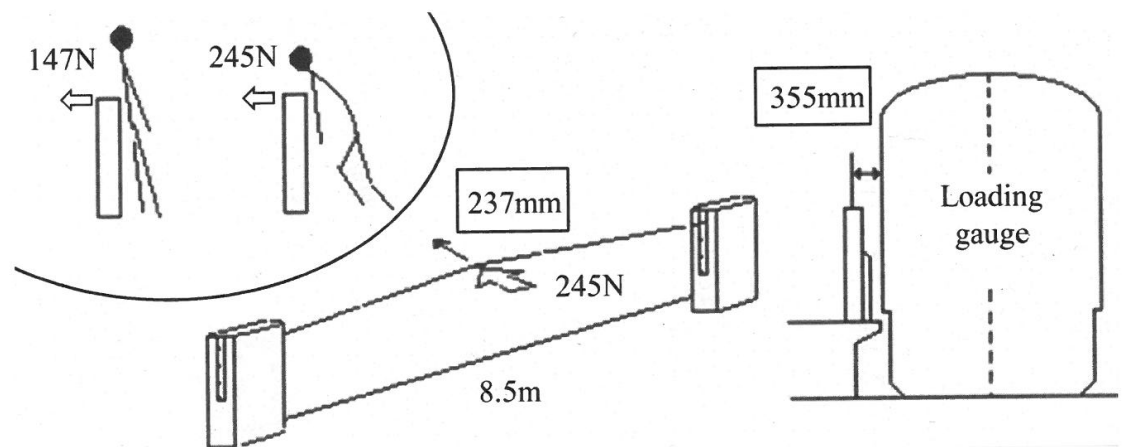

Figure 5: Elongation of wire.

\section{Passenger sensing system}

This section describes the passenger sensing system. To prevent passengers from being injured by moving wires, infrared sensors were installed on the platform side of the gates. Basically, the wires stop moving when the sensors detect something. However, several operating modes were programmed in to maintain stable movement of trains and passengers (Figure 6).

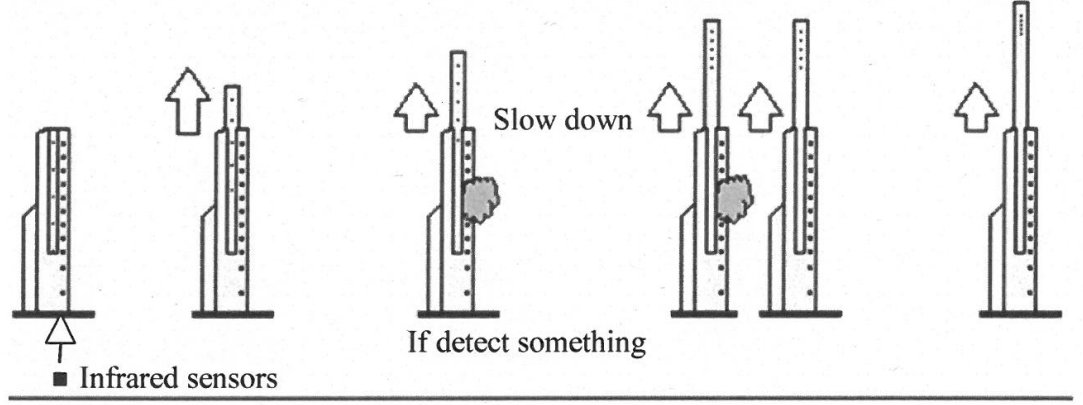

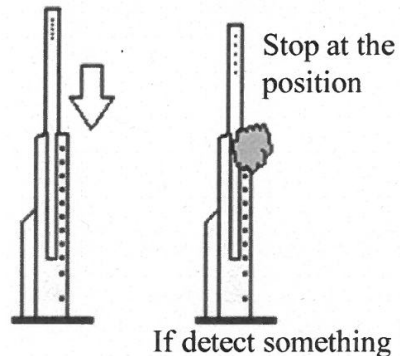

by the top sensor

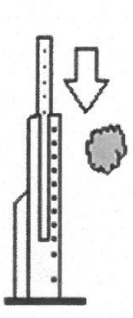

If detect something by other sensors

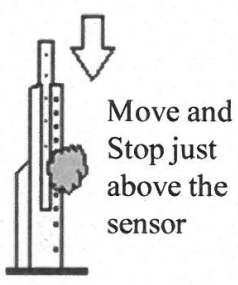

Stop just above the sensor

Figure 6: Movement control. 
Since people tend to step close to the doors, the upward movement of wires was programmed not to "stop" but to "move slowly", even if sensors detect something.

The downward movement of wires was programmed differently, depending upon which sensor is alarmed. When the sensor at the top of the pillar detects something, the wires stop at that position to prevent contact with anything existing below. In addition, passengers with large bags may unknowingly block the lower sensors as they walk along the platform. In this case, if all but the top sensor is alarmed, the downward movement of wires is slowed until they reach just above the alarmed sensor.

There are two types of sensors installed on the rail side, i.e., infrared sensors and 3D sensors (Figure 7). These were designed to provide error free detection of passengers between the train and the gates. If these sensors detect something while the wires are closing, the gate immediately freezes at its current position.

To prevent passengers from being injured by moving pillars, pressure sensors were installed on top of the body in front of where the wires pass, and infrared sensors cover the area where the pillar slides up and down.

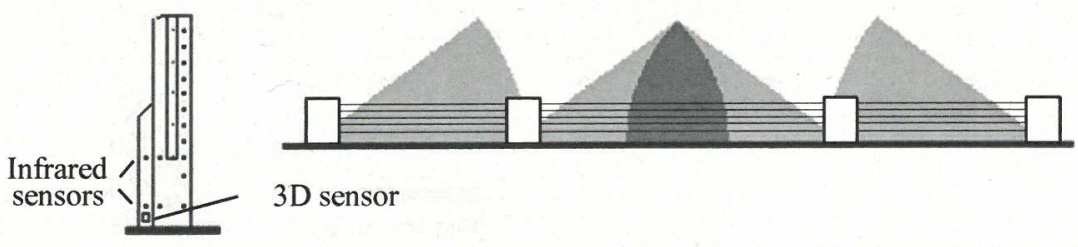

Figure 7: Sensors on the rail side.

\section{Systems for detecting trains}

This section shows how the different train car configurations are detected, how drivers and conductors recognise movement of the gates, and how the conductor handles the gates. These systems were developed in concert with the Nabtesco Corporation.

\subsection{Sensing the train configurations}

Trains with $6,7,8,10$ and 12 car configurations stop at Rokkomichi station, which has two stopping markers, one for 10 and 12 cars, and the other for 6,7 and 8 cars. 

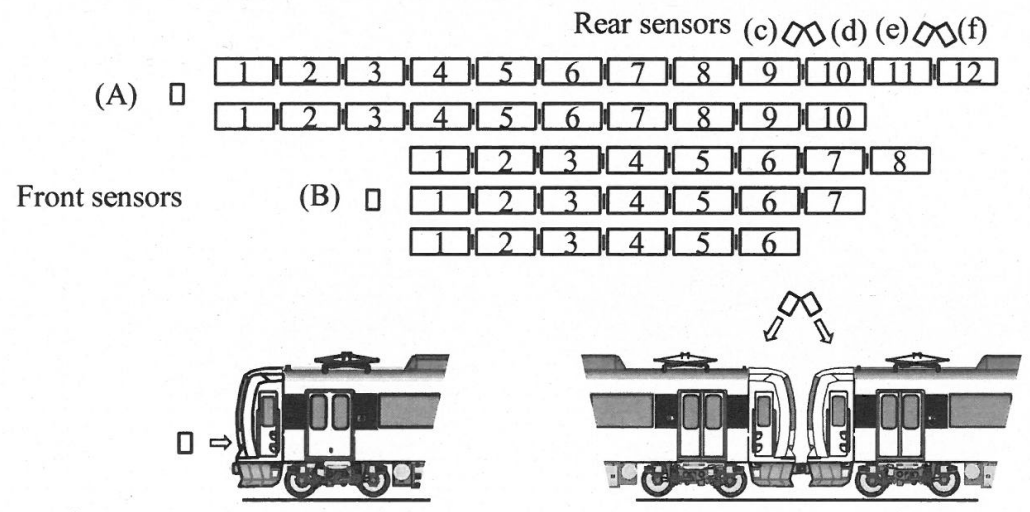

Figure 8: Allocations of front and rear sensors.

Table 2: Combination of detection of sensors and train configurations.

\begin{tabular}{|c|c|c|c|c|c|c|}
\hline \multicolumn{2}{|c|}{ Front sensors } & \multicolumn{4}{|c|}{ Rear sensors } & \multirow[t]{2}{*}{ Car configurations } \\
\hline $\mathrm{A}$ & $\mathrm{B}$ & $\mathrm{c}$ & $\mathrm{d}$ & $\mathrm{e}$ & $\mathrm{f}$ & \\
\hline 0 & $x$ & O & O & o & 0 & 12 \\
\hline 0 & $x$ & o & O & $\times$ & $x$ & 10 \\
\hline$\times$ & 0 & 0 & 0 & ○ & $\times$ & 8 \\
\hline$x$ & 0 & 0 & 0 & $\times$ & $x$ & 7 \\
\hline$x$ & 0 & O & $x$ & $\times$ & $x$ & 6 \\
\hline
\end{tabular}

Trains that stop within the allowable range (i.e., $+/-1,000 \mathrm{~mm}$ ), are detected by sensors located $1,500 \mathrm{~mm}$ in front of the stopping markers, which can measure distance to the train even if it stops over $1,000 \mathrm{~mm}$ away from the stopping marker. Four rear sensors are set at the tail end to check whether a car exists in the area each sensor covers (Figure 8).

With this combination of front and rear sensors, the train configuration is detected and the gates with cars open (Table 2).

\subsection{Signs for drivers and conductors}

When a train stops within the allowable area, two blue signals (one each for the driver and conductor) indicate that the train has "stopped within the allowable range" and the gates open automatically. Red signals indicate "gates are opening", "gates are opened" and "gates are closing", which tells driver and conductor that the gates are not closed. When gates are closed, and there is nothing detected by the sensors on the rail side, the red signals are extinguished and a white signal then indicates to the driver that the train is "able to depart" (Figure 9). 


\begin{tabular}{|c|c|c|c|c|c|}
\hline & Driver & Conductor & & Driver & Conductor \\
\hline $\begin{array}{l}\text { Stopped within the } \\
\text { allowable range }\end{array}$ & $\begin{array}{l}\square \\
\text { blue }\end{array}$ & b blue & $\begin{array}{l}\text { Stopped } \\
\text { out of range }\end{array}$ & 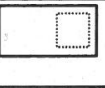 & \begin{tabular}{|ll|l|}
1 & & \\
& & \\
\end{tabular} \\
\hline Gates are opening & \multirow{3}{*}{ red } & $\begin{array}{lll}0 & & \\
4 & & \end{array}$ & & & \\
\hline Gates are opened & & $\begin{array}{lll}\Uparrow \sqrt{n} & \text { red }\end{array}$ & & & \\
\hline Gates are closing & & in red & & & \\
\hline \multirow[t]{2}{*}{ Gates are closed } & $0 \square$ & \multirow{2}{*}{ ( } & \multirow{2}{*}{$\begin{array}{l}\text { Something exists } \\
\text { between the } \\
\text { train and gates }\end{array}$} & 2 & \multirow{2}{*}{ 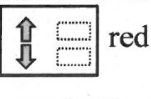 } \\
\hline & white & & & red & \\
\hline
\end{tabular}

Figure 9: Signals to drivers and conductors.

\section{Operational results}

The wire style platform gates were installed in Rokkomichi Station on 13th December and have worked successfully with no significant problems.

In one month's time, train delays of more than 1 minute that were due to malfunctioning gates occurred only eight times among 14,000 train cycles. Insufficient adjustment of the optical axis on a pair of infrared sensors caused them to malfunction in heavy rain, and as a result two trains were delayed for one minute. Peeling insulation short-circuited a pressure sensor, causing a train to be delayed for three minutes. These three failures were attributed to poor installation work. Five other delays were due to heavy snow deposits on the surface of the sensors, which functioned properly once they were cleaned.

According to a survey conducted by the company at the station, 90 per cent of the passengers welcomed the increased level of safety provided by the gates and supported further installations in other stations.

\section{Conclusion}

Results of this study indicate that installation of the gates has a positive impact on improving safety without negatively impacting passenger flow and train operation. As a result, JR-West is currently considering additional installations at other stations throughout the JR-West area to further reduce platform accidents.

The next challenge is to install the gates in stations where express trains with car lengths of 21.1 meters stop. The doors locations are more complicated, and the distance between the platform gate pillars widens to 12 meters. 


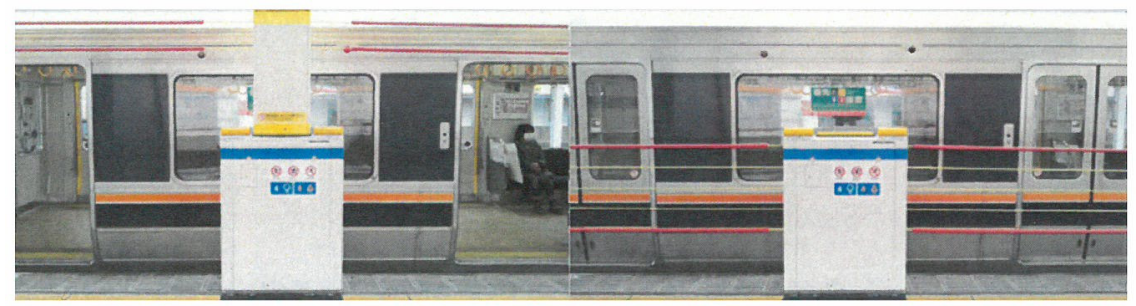

Figure 10: Side view of the wire style platform gates (open/close).

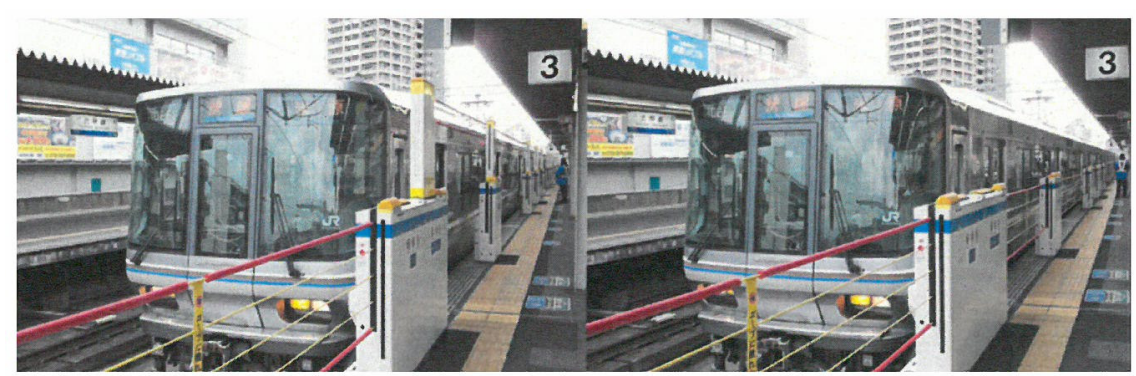

Figure 11: Front view of the wire style platform gates (open/close).

Decreasing the cost of installation will also be necessary. The company has to develop more efficient methods of reinforcing earth-filled platforms, the cost of which can add up more than double of that of installing the gates themselves.

By finding good solutions to such issues, the company is committed to increasing the level of platform safety by carrying forward with installation of platform gates.

\section{References}

[1] Institute for Transport Policy Studies, Railways described by figures 2008, Institute for Transport Policy Studies, p12, 2008

[2] Ministry of Land, Infrastructure, Transport and Tourism of Japan, Interim report to prevent passengers from falling off from platforms, MLIT Website, www.mlit.go.jp/tetudo/tetudo tk6_000017.html

[3] Ministry of Land, Infrastructure, Transport and Tourism of Japan, Stations with platform doors in Japan at the end of sep.2014, MLIT Website, www.mlit.go.jp/tetudo/tetudo tk6 000022.html

[4] JR-West, JR-West described by data, JR-West, p26.27, 2014 